\title{
SOBREVIVÊNCIAS PESSOANAS: ENRIQUE VILA-MATAS LENDO O BARÃO DE TEIVE
}

\author{
Kelvin dos Santos Falcão Klein ${ }^{1}$
}

\begin{abstract}
RESUMO: Onde encontrar Fernando Pessoa na literatura contemporânea? Há lugar para ele? Este ensaio rastreia possíveis respostas na ficção do escritor espanhol Enrique Vila-Matas, especificamente no resgate que faz de um semi-heterônimo de Pessoa: o Barão de Teive. Bartleby \& companhia, romance composto de comentários fragmentados sobre a obra de escritores que abandonaram a literatura (os "artistas do Não"), incorpora o jogo heteronímico de Pessoa e atualiza questões como a vacuidade do Eu no discurso e o embate entre silêncio e linguagem que toma lugar no cerne da literatura. A hipótese é a de que Pessoa, representado por seu semi-heterônimo, sobrevive em chave anacrônica na leitura de Vila-Matas, conferindo sentido retrospectivo a certas lacunas da história literária, sobretudo no que diz respeito às vanguardas do início do século XX.
\end{abstract}

PALAVRAS-CHAVE: Literatura contemporânea. Barão de Teive. Intertextualidade.

ABSTRACT: Where to find Fernando Pessoa in the contemporary literature? Is there a place for him? This essay tracks answers on Spanish writer Enrique Vila-Matas' fiction, specifically in the rescue that he does of a semi-heteronym of Pessoa: Baron of Teive. Bartleby \& companhia, novel made of fragmentary commentaries about writers that abandoned literature (the "artists of No"), incorporates the heteronimic game of Pessoa and updates issues such as the emptiness of I in the speech and the struggle between silence and language that takes place in the heart of literature. The hypothesis is that Pessoa, represented by his semi-heteronym, survives on anachronical key on Vila-Matas' reading, giving retrospective meaning to gaps of the literary history, especially on early twentieth century vanguards.

KEY WORDS: Contemporary Literature. Baron of Teive. Intertextuality.

Como abordar a imensa cidade de sentido que é Fernando Pessoa? Como fazer para percorrê-la sem ser esmagado pela grande quantidade de possibilidades que ela guarda em si? É necessário procurar um ponto menos visado, uma face da muralha que esteja mais à penumbra, para que essa aparente tranqüilidade inspire a coragem necessária para começar. Assim parece ter feito o escritor espanhol Enrique Vila-Matas, quando, em seu livro Bartleby \& companhia, publicado originalmente pela Editorial Anagrama em 2000, resgata Pessoa a partir de um semi-heterônimo de obra mínima e vida breve: o Barão de Teive.

\footnotetext{
${ }^{1}$ Professor Mestre em Literatura Comparada pela Universidade Federal do Rio Grande do Sul (UFRGS), com dissertação sobre a intertextualidade em Enrique Vila-Matas. Doutorando em Teoria Literária na Universidade Federal de Santa Catarina (UFSC).
} 
Álvaro Coelho de Athayde, décimo quarto Barão de Teive, foi traçado por Pessoa entre 1928 e 1929, em um caderno de capa preta. Teve uma infância marcada pela solidão, uma estreita ligação com a mãe, que morreu quando o Barão já era adulto, teve uma vida abastada em uma quinta nos arredores de Lisboa e viajou bastante ao exterior, principalmente Paris. Enfrentava sérias dificuldades em lidar sexualmente com mulheres. O Barão teve a perna esquerda amputada, pouco tempo antes de se suicidar, fato que ocorreu em 11 de julho de 1920. Escreveu uma única obra, $A$ educação do estóico, uma espécie de subtexto, de escritura que acontece como comentário a um discurso que já não mais existe, uma vez que o Barão declara: "Não me arrependo de ter queimado o esboço todo das minhas obras. Não tenho mais a legar ao mundo que isto." (PESSOA, 2006, p. 32).

A primeira edição completa da obra atribuída a Teive só foi publicada em 2001, em Portugal, pela Editora Assírio \& Alvim. A edição brasileira é de 2006, pela Editora A Girafa. Richard Zenith, responsável pelo estabelecimento do texto e pela organização dos trechos dispersos, afirma que alguns excertos da obra de Teive já haviam sido publicados como pertencentes ao Livro do Desassossego, e figuram também em prefácios de algumas edições de livros de Pessoa, como as de Maria Aliete Galhoz e Teresa Rita Lopes. Zenith, em seu prefácio à obra, afirma que os fragmentos de Teive "são de difícil leitura e de difícil arrumação, consistindo sobretudo em apontamentos e esboços destinados a um desenvolvimento posterior" (PESSOA, 2006, p. 10). Ou seja, essa é uma parte da obra de Pessoa que permanece aberta, em potência, como que lançada ao futuro, sem resolução ou sentido fixo - oscilação que permeia tanto forma quanto conteúdo.

Teive foi concebido como uma figura do extremo e do limite, utilizada como teste de intensidade poética. Em um escrito auto-interpretativo, Pessoa afirma: "Transferi para Teive a especulação sobre a certeza, que os loucos têm mais que nós" (PESSOA, 2006, p. 61). Contudo, já no início de suas notas, o Barão mostra que a única certeza que professa é aquela que remete ao "conhecimento íntimo da vacuidade de todos os esforços e da vaidade de todos os propósitos" (PESSOA, 2006, p. 17). Teive especula ininterruptamente sobre a certeza da incerteza. Está no subtítulo de sua obra: $a$ impossibilidade de fazer arte superior, o que remete sempre ao ato extremo do semiheterônimo de queimar toda sua obra. Um ato extremo que, aos olhos de Pessoa, só 
poderia ser cometido por um louco. É importante observar o quão próximo Teive está de Pessoa: sabemos que o último só publicou, em vida e como livro, Mensagem, mas que escreveu compulsivamente, guardando seus manuscritos em uma arca - a arca está para Pessoa como o forno está para Teive: signos que relembram a impossibilidade de fazer arte superior e a vaidade de todos os propósitos. O silêncio acompanha de perto, portanto, todo o desenvolvimento da obra de Pessoa.

Enrique Vila-Matas, muitos anos depois, resgata Pessoa e o reposiciona na cena contemporânea a partir da figura do Barão de Teive, configurado como personagem de uma galeria muito eloquente na história da literatura: aquela que congrega o que VilaMatas denomina "artistas do Não" (VILA-MATAS, 2004, p. 12). Nascido em Barcelona em 1948, Vila-Matas, desde sua estréia literária em 1985 com Historia abreviada de la literatura portátil, sempre exerceu uma ficção híbrida, tomando escritores e ideias críticas como motores de seus textos, testando os limites dos gêneros e ampliando as possibilidades criativas do ato da leitura. Seus livros sempre remetem a outros livros, em uma trama intertextual que trabalha em uma sobreposição contínua de temporalidades. Bartleby \& companhia é um romance composto de 86 pequenos capítulos, notas de leitura reunidas ao redor de um único tema: os escritores que abandonaram a literatura. $\mathrm{O}$ narrador, escritor frustrado, funcionário público em licença de saúde, aproveita o tempo livre para acumular histórias e comentários sobre escritores como Rimbaud, Juan Rulfo, J. D. Salinger, Herman Melville, Julien Gracq, Leopardi e, claro, o Barão de Teive. O desejo do narrador é o de escrever "notas de rodapé que comentarão um texto invisível, mas nem por isso inexistente" (VILA-MATAS, 2004, p. 11).

O procedimento de Vila-Matas é semelhante ao do Barão, só que ampliado. O Barão constrói um discurso que reflete sua própria impotência, diante da vida e da literatura; o narrador de Vila-Matas procura disseminar sua angústia do vazio pessoal por uma lista vastíssima de escritores. Literatura e vida são mescladas, em diversos níveis: as primeiras palavras de Bartleby \& companhia são: "Nunca tive sorte com as mulheres, suporto com resignação uma penosa corcunda" (VILA-MATAS, 2004, p. 9) o Barão, por sua vez, além da perna amputada, declara que "as raparigas que não seduzi foram seduzidas por outros" (PESSOA, 2006, p. 40). Nessas duas visões complementares, tanto o sexo quanto a escritura são caminhos que levam ao vazio, 
remetem antes à proliferação do caos do que à ordem. Isso fica evidente quando pensamos na forma com que se arma tanto A educação do estóico, de Teive, Bartleby \& companhia, de Vila-Matas, e o Livro do Desassossego, de Bernardo Soares.

A entrada deste terceiro elemento justifica-se por conta de um texto de Fernando Pessoa, destinado ao prefácio das Ficções do Interlúdio, que Zenith cita em seu comentário. Escreve Pessoa: "Bernardo Soares e o Barão de Teive - são ambos figuras minhamente alheias - escrevem com a mesma substância de estilo, a mesma gramática, e o mesmo tipo e forma de propriedade: é que escrevem com o estilo que, bom ou mau, é o meu" (PESSOA, 2006, p. 89). Pessoa, Teive e Soares, portanto, confluem em um ponto, que aqui depreenderemos do texto do Barão: os três cultivam a consciência da impossibilidade de fazer arte superior - e, a partir daí, colocam em cena uma escritura que é sempre esboço, potência e devir, fugindo sempre dos pontos de vista fixos. $\mathrm{O}$ Livro do Desassossego é na forma aquilo que mostra em seu conteúdo: fragmentos em permanente oscilação (como fica evidente a cada edição que surge: sempre aparecem rearranjos e novas disposições). Fernando Pessoa, em seus últimos anos, viu-se com páginas e páginas de um Fausto que foi só projeto, centenas de poemas inacabados, pedaços de peças de teatro, além de uma sucessão de planos, esquemas e listas que nunca se tornaram mais do que isso.

Vila-Matas dá um passo além, pois incorpora o caos, utilizando-o como metaquestionamento acerca da literatura, valendo-se da consciência da impossibilidade de fazer arte superior para determinar a totalidade como uma ferramenta obsoleta. Não à toa Pessoa está aí, representado pela figura do Barão de Teive: é também dele que VilaMatas retira a noção de que "a essência de qualquer texto consiste precisamente em fugir de toda determinação essencial, de toda afirmação que o estabilize ou realize." (VILA-MATAS, 2004, p. 167). Seu livro é como um caderno de capa preta de Pessoa, publicado como está, em sua arbitrariedade de comentário a um texto invisível. Suas notas são erráticas como são as do Livro do Desassossego: a nota 33 fala do Barão, as duas notas anteriores falam, respectivamente, de J. D. Salinger e Jorge Luis Borges, as duas notas subseqüentes, de Hugo von Hofmannsthal e Paul Celan. Estas e todas as outras notas procuram testemunhar o silêncio e a negatividade do dizer, o balbucio da linguagem que aflora em toda sua indecidibilidade, reiterando aquilo que escreveu o 
Barão: "Tudo, quando penso ou sinto, inevitavelmente se me volve em modos de inércia." (PESSOA, 2006, p. 36).

Dessa inércia, descortina-se uma dimensão trágica no Barão de Teive, que Bartleby \& companhia ressalta, colocando em mutação mediante o contato com outros casos. Escreve o Barão que "o homem tem somente, de seu e próprio, a honra ou o silêncio. Senti isso, mais que nunca, nas chamas do fogão em que acabei para sempre com os meus escritos." (PESSOA, 2006, p. 52). No silêncio, o homem defronta-se com um nível de percepção do mundo que, enquanto reforça a consciência, engrandece também a angústia. No silêncio, o homem desaparece para as intervenções do senso comum e renova uma comunhão solitária com a linguagem. Esse silêncio percorre toda a argumentação do Barão, cristalizado no fogo que fez desaparecer sua obra.

Se seguirmos Richard Zenith quando este afirma que muitas das questões levantadas por Teive já preocupavam Pessoa desde a década de 10 (PESSOA, 2006, p. 95), poderemos articular esse resgate recente do Barão (essa sobrevivência pessoana) com um escritor contemporâneo de Pessoa: Franz Kafka. Nesse mesmo período (por volta de 1914), Kafka escreve um fragmento sobre as sereias, que, entre outras coisas, anunciava: "As sereias entretanto têm uma arma ainda mais terrível que o canto: o seu silêncio." (KAFKA, 2002, p. 104). Interessante ressaltar o contato da figura feminina com o fazer literário, incitando o discurso (como forma de sublimação sexual, como Zenith e outros afirmam sobre Pessoa (ver, por exemplo, O caso clínico de Fernando Pessoa (SARAIVA, 1994))) e levando-o ao silêncio - a sereia de Kafka está para a rapariga de Teive e ambas são signos que remetem à sempre mencionada impossibilidade de fazer, agir e produzir.

É conhecido, também, o desejo final de $\mathrm{Kafka}^{2}$, transmitido a seu amigo mais próximo, Max Brod: era preciso queimar toda sua obra assim que ele morresse - desejo que não foi respeitado. No caso de Teive, um fogo já ocorrido determinou a realização de sua única obra conhecida. No caso de Kafka, um fogo profético, ainda no futuro, em potência, organizou as linhas de força de sua obra. Ambos são discursos que cortejam o

\footnotetext{
${ }^{2} \mathrm{O}$ tradutor Modesto Carone, em seu posfácio de Narrativas do Espólio, especifica a questão: "Voltando ao acervo deixado pelo escritor tcheco após sua morte, em 1924, não é possível passar ao largo do episódio da destruição a que ele foi condenado pelo próprio autor. O mandatário e protagonista rebelde dessa tarefa expressamente recusada foi, como se sabe, o amigo e testamenteiro Max Brod - e aqui vale recordar que, no espólio de Kafka, havia dois testamentos dispondo sobre a queima de sua herança literária. (A esta altura é útil salientar que apenas um sexto da obra kafkiana veio à luz enquanto ele era vivo)." (KAFKA, 2002, p. 216).
} 
silêncio, problematizando a questão da sobrevivência possível de um texto e dos resíduos que ele deixa com a ação do tempo.

Maurice Blanchot, em muitos de seus ensaios, espalhados ao longo de seus anos de atividade, pensa a articulação do silêncio com a literatura e seu contínuo fluxo de impossibilidade. Em O paradoxo de Aytré, artigo publicado em 1946 no nono volume da revista Les Temps modernes (fundada no ano anterior por Sartre, Simone de Beauvoir e Merleau-Ponty), no qual Blanchot analisa uma narrativa do escritor francês Jean Paulhan, está registrado que "o silêncio faz parte da linguagem, cuja ausência ele demonstra (...) Meu silêncio me faz participar inteiramente do sentido que lhe atribuo." (BLANCHOT, 1997, p. 66). Blanchot afirma que o objetivo de toda comunicação é atingir o silêncio, a situação inicial de tudo que é dito, como uma pulsão de morte da linguagem, que anseia pelo estado primordial de pré-existência. A literatura acontece, em Teive, Kafka e Vila-Matas, na negação desse destino, no auto-engano dos escritores, que justificam suas obras pela presença de outras vozes em seu interior, vozes que os atravessam continuamente, enquanto lutam contra o solipsismo radical que envolve o ato da escritura. A literatura é feita do ir e vir desses opostos: "o silêncio está longe de ser o oposto da língua; pelo contrário, só há linguagem no silêncio.” (BLANCHOT, 1997, p. 70).

Esse horizonte crítico percorre, também, a produção tradutória de Fernando Pessoa. Consta que, por volta de 1915, o poeta português traduziu o livro $A$ voz do silêncio, de Helena Blavatsky. Este livro, contudo, oferece uma gênese muito mais complexa. Trata-se de um dos textos mais importantes da chamada literatura teosófica, sendo, na verdade, a tradução para o inglês de um antigo texto religioso tibetano. É, portanto, um tratado esotérico que lida com a iluminação da linguagem (e da experiência) pela via do silêncio e, novamente, pela consciência da impossibilidade que permeia essa mesma linguagem. Pessoa teve contato com a doutrina teosófica e com os escritos de Blavatsky, traduzindo-os ao português, no mesmo período em que fermentava as ideias do Barão de Teive sobre a queima dos manuscritos, a invasão da linguagem pelo silêncio e a vaidade de toda empresa humana (período em que Kafka escrevia sobre o silêncio das sereias, como assinalei).

A voz do silêncio, na tradução de Pessoa, teve uma primeira edição extremamente tardia, publicada no Brasil em 1969 pela Civilização Brasileira. A 
primeira edição em Portugal, pela Assírio \& Alvim, foi publicada somente em 1998. Há uma reedição brasileira corrente, pela editora Ground, de São Paulo. Nesta edição, Murillo Nunes de Azevedo, autor do estudo introdutório, cita uma carta de Pessoa a Mario de Sá-Carneiro, datada de 6 de dezembro de 1915, na qual o poeta afirma "ter tomado conhecimento das doutrinas teosóficas", e finaliza: "O modo como as conheci foi banalíssimo. Tive de traduzir livros teosóficos.” (BLAVATSKY, 2002, p. 23). E Pessoa seguiu traduzindo, informa Murillo Nunes: "Abalou-me a um ponto que eu julgaria hoje impossível, tratando-se de qualquer sistema religioso." (BLAVATSKY, 2002, p. 25).

Vemos que, na ampliação desse percurso, expressões fundamentais são postas em cena: "a voz do silêncio", apropriada por Pessoa da Teosofia e burilada como “impossibilidade de fazer arte superior"; uma "educação do estóico", que aprende com "o silêncio das sereias", que nomeia o fragmento de Kafka. Voltando a Blanchot, temos "a parte do fogo", título de um de seus livros, que contém o ensaio sobre o paradoxo de Aytré, "fogo" que foi sugerido pelo ato extremo do Barão de queimar seus escritos. Pessoa cultivou esse enigma do ocultamento (o fogo e a arca) em seus heterônimos e semi-heterônimos, Blanchot expandiu e rastreou o ocultamento que promove o fogo em vários momentos da literatura mundial (Hölderlin e Heráclito, por exemplo, que servem de epígrafes ao livro $A$ parte do fogo). Quando resgatamos a queima da obra que toma lugar tanto em Teive quanto em Kafka, resgatamos também uma sucessão de temporalidades que se comunicam e que não respeitam a simples cronologia, pois são ativadas mediante contato.

Há um fundo religioso em tudo isso, sem dúvida, como já fica evidente na Teosofia de Pessoa, mas que se espalha principalmente na Cabala, compartilhada por Pessoa, Kafka e Blanchot ${ }^{3}$. O silêncio e a impossibilidade relacionam-se, nesse ponto, com a temática do conhecimento proibido - que o historiador Carlo Ginzburg localiza como ponto de referência para se pensar o alto e o baixo tanto no contexto cultural quanto no contexto religioso (GINZBURG, 1989, p. 95-118). Quando o Barão fala que

\footnotetext{
${ }^{3}$ Escreve Philip Beitchman, em seu livro Alchemy of the word: cabala of the Renaissance : "For Blanchot, as well as for Harold Bloom, Cabala would convey, from a literary point of view, a language-oriented protomodernism, in the ways in which it reflects incessantly on the status of the oral and the written, making of the latter a question that can neither be answered nor dismissed, that indeterminate expression of an 'ethic of ambiguity' we've agreed to call text." (BEITCHMAN, 1998, p. 29). A Cabala compreendida, portanto, como uma teoria da textualidade que leve em conta também as lacunas do sentido, ou seja, os silêncios.
} 
"a dignidade da inteligência está em reconhecer que é limitada e que o universo está fora dela" (PESSOA, 2006, p. 55), e quando dá por certo (natural) a existência de uma arte superior (que remete, inquestionavelmente, a uma arte inferior), remonta a um contexto de normatividade sobre o que pode ser dito, pensado ou refletido. Ginzburg vai até a epístola de Paulo aos Romanos, mostrando como um versículo de cunho moral transformou-se em norma intelectual, passando da ordem da convivência entre hebreus e romanos para uma extensa desculpa para o obscurantismo (GINZBURG, 1989, p. 95), equívoco que durou séculos, já que, segundo Ginzburg, "a passagem ligava-se originalmente ao bom senso e não ao conhecimento" (GINZBURG, 1989, p. 114). Esse é um contato agônico entre palavra e silêncio que surge (na argumentação de Ginzburg (pois os pontos de partida podem variar)) com o apóstolo Paulo, passa pela tradução de São Jerônimo da Bíblia (Vulgata), alcança o humanista Erasmo de Roterdã e comentaristas bíblicos como Tomás de Kempis e John Donne, até chegar em Maurice Blanchot, Fernando Pessoa e Franz Kafka.

Leyla Perrone-Moisés, em seu livro Fernando Pessoa, aquém do eu, além do outro, ao dissertar sobre o silêncio no contato com a linguagem, em aporte lacaniano, agrega mais um termo ao cenário delineado até aqui: "significante vazio". Sujeito e linguagem se mesclam na vacuidade da palavra, pois, segundo Perrone-Moisés, “quando se diz eu, produzem-se imediatamente vários: o sujeito da enunciação, o sujeito do enunciado e o referente; e ninguém: porque o referente aí é apenas relacional e não substancial." (PERRONE-MOISÉS, 1982, p. 80). A autora diz que "a experiência de Pessoa, nesse campo, é uma das mais agudas e constantes de que se tem notícia”, uma vez que sua "poesia toda tematiza esse saber de linguagem: a linguagem como ausência da coisa (o que ela é sempre) e, sobretudo, como ausência do Eu" (PERRONEMOISÉS, 1982, p. 81). Pessoa como significante vazio aparece como a possibilidade de oscilação do sentido, simultaneamente preenchido de alto e baixo, voz e silêncio, sem com isso incorrer em homogeneização ou generalização, uma vez que a configuração desse vazio é única, está construído a partir da idiossincrasia dos relevos de estilo de Pessoa - mais do que um significante vazio, um vazio significante.

Portanto, a partir disso, é possível concluir que o resgate que Enrique Vila-Matas propõe, tanto do Barão de Teive quanto de Fernando Pessoa ele-mesmo, atualiza o jogo de identidades cambiantes que encontramos em Pessoa. Além disso, posiciona o poeta 
português como ator ativo do cenário literário contemporâneo, a partir de uma leituraescritura que explora justamente os pontos ainda não escritos da poética de Pessoa, os pontos que comungam do fogo e do silêncio. Vila-Matas empreende, inclusive, uma atualização do jogo heteronímico, já que incorpora às notas de Bartleby \& companhia escritores que não existem, sem, contudo, indicar quais nomes citados são reais e quais são apócrifos. Essa mescla, aliada ao anacronismo criativo que ressuscita o Barão, confere ao esforço ficcional de Vila-Matas uma vasta gama de possibilidades de reler a história literária, de dentro para fora. "A falta é a condição para que o desejo continue a circular", observa Leyla Perrone-Moisés (1982, p. 6), e, quando encontramos Pessoa em Vila-Matas, disseminado, proliferado e incerto, atualizado em toda sua falta e na plenitude de sua vacuidade, sentimos a literatura operar para a circulação desse desejo de múltiplas faces, múltiplas vozes e sempre tão fugidio.

\section{Referências bibliográficas:}

BEITCHMAN, Philip. Alchemy of the word: cabala of the Renaissance. New York: State University of New York Press, 1998.

BLANCHOT, Maurice. A parte do fogo. Trad. Ana Maria Scherer. Rio de Janeiro: Rocco, 1997.

BLAVATSKY, Helena. A voz do silêncio. Trad. Fernando Pessoa. São Paulo: Ground, 2002.

GINZBURG, Carlo. Mitos, emblemas, sinais: morfologia e história. Trad. Federico Carotti. São Paulo: Companhia das Letras, 1989.

KAFKA, Franz. Narrativas do espólio. Trad. Modesto Carone. São Paulo: Companhia das Letras, 2002.

PERRONE-MOISÉS, Leyla. Fernando Pessoa, aquém do eu, além do outro. São Paulo: Martins Fontes, 1982.

PESSOA, Fernando. A educação do estóico. Barão de Teive. São Paulo: A Girafa Editora, 2006.

SARAIVA, Mário. O caso clínico de Fernando Pessoa. Lisboa: Editorial Referendo, 1994.

VILA-MATAS, Enrique. Bartleby \& companhia. Trad. Maria Carolina de Araújo e Josely Vianna Baptista. São Paulo: Cosac Naify, 2004. 